\title{
BMJ Open Job demands and resources and their relationship with satisfaction and thriving at work in a sample of Chinese doctors: a cross-sectional study
}

\author{
Shu'e Zhang, ${ }^{1}$ Yu Shi, ${ }^{1,2}$ Bei Liu, ${ }^{3}$ Hongni Wang (D,${ }^{4}$ Xin Zhao, ${ }^{4}$ Xiaohe Wang, ${ }^{4}$ \\ Tao Sun (1) ${ }^{4}$
}

To cite: Zhang S, Shi Y, Liu B, et al. Job demands and resources and their relationship with satisfaction and thriving at work in a sample of Chinese doctors: a crosssectional study. BMJ Open 2021;11:e045745. doi:10.1136/ bmjopen-2020-045745

- Prepublication history for this paper is available online. To view these files, please visit the journal online (http://dx.doi. org/10.1136/bmjopen-2020045745).

Received 10 October 2020 Accepted 09 0ctober 2021

\section{Check for updates}

(c) Author(s) (or their employer(s)) 2021. Re-use permitted under CC BY-NC. No commercial re-use. See rights and permissions. Published by BMJ.

${ }^{1}$ Department of Health Management, School of Health Management, Harbin Medical University, Harbin, Heilongjiang, China

${ }^{2}$ Vanke School of Public Health, Tsinghua University, Beijing, China

${ }^{3}$ Department of Inspection, School of Public Health, Beijing University, Beijing, China ${ }^{4}$ Department of Department of Health Management and Policy, School of Public Health, Hangzhou Normal University, Hangzhou, Zhejiang, China

Correspondence to Professor Tao Sun; hydsunta0@126.com

\section{ABSTRACT}

Objectives The current study aimed to evaluate the status quo of perceived job demands and resources respectively among Chinese doctors, to examine the mediating role of work-family conflicts in the relationship between perceived job demands and various indicators of wellbeing, and to test the mediating role of psychological attachment in the relationship between perceived job resources and thriving at work among Chinese doctors. Design A cross-sectional online survey study.

Setting Online questionnaires were administered across 30 provinces.

Participants A total of 2617 doctors provided sufficiently complete responses to be used in the study.

Results Perceived job demands $(M=3.843, S D=0.791)$ of participants were positively associated with work-family conflicts $(B=0.454, p<0.001)$ and negatively associated with job satisfaction $(B=-0.065, \mathrm{p}<0.001)$ and life satisfaction $(B=-0.261, \mathrm{p}<0.001)$. Work-family conflicts partially mediated the relationship between job demands and life satisfaction and fully mediated the relationship between job demands and job satisfaction. Perceived job resources $(M=2.474, S D=0.740)$ among Chinese doctors were positively associated with psychological attachment $(B=0.988, \mathrm{p}<0.001)$ and thriving at work $(B=0.582$, $p<0.001)$. Furthermore, psychological attachment partially mediated the relationship between perceived job resources and thriving at work.

Conclusion Doctors in China with high-level job demands tended to exhibit increased work-family conflicts, which in turn threatened their job and life satisfaction. On the contrary, doctors with greater job resources were more likely to thrive at work by increasing their degree of psychological attachment. The current study suggested that Chinese health policymakers and hospital administrators should provide a work environment with a dynamic equilibrium between doctors' job demands and resources.

\section{BACKGROUND}

China's healthcare system is facing new challenges, with growing demands and expenditures in healthcare services and inefficient utilisation and imbalanced distribution of health resources. ${ }^{1}$ The shortage of human
Strengths and limitations of this study

- A series of hierarchical linear regression analyses were performed to examine the relationships among the variables.

- Mediation analyses were performed to explore the mechanism between job demands and resources and job well-being.

- The cross-sectional nature of the variables hindered the establishment of causal relationships between outcomes.

- A convenience sample tended to increase potential sampling bias.

Data were collected through an online questionnaire.

resources in the health sector of China, which has a large population, is a contributing factor and has drawn both social and political concerns. ${ }^{2}{ }^{3}$ Ideally, doctors' work should be engaging, motivating and meaningful, thus contributing to greater personal thriving, higher well-being, optimal health outcomes and better performance. However, a 2014 national survey has shown that approximately $92 \%$ of doctors in tertiary hospitals experienced working overtime and $72 \%$ working more than 60 hours a week on average. ${ }^{4}$ Most of them were also in poor physical condition. ${ }^{4}$ Moreover, Chinese doctors are often victims in China's current healthcare system, facing challenges associated with workplace violence, ${ }^{4}$ heavy workload, overwork and work overload, and occupational burnout. ${ }^{5} \mathrm{~A}$ national survey revealed that approximately $83.4 \%$ of doctors have suffered more than one sort of workplace violence ${ }^{6}$ and about $85.79 \%$ of Chinese doctors have reported suffering from burnout. ${ }^{5}$ Additionally, there is a disproportionate coverage in media, television and social websites ${ }^{17}$ on how healthcare providers have cheated customers and presented unfriendly service attitudes 
towards patients, provoking further tension relationships in both sides. ${ }^{2}{ }^{3}$ This might trigger a series of adverse consequences, including decreased work functioning, increasing physicians' psychosocial stress and job dissatisfaction in a vicious spiral. In the field of occupational medical research and practice, the job demands-resources (JD-R) model recently attracted attention with regard to attaining ideal occupation, optimal health and well-being for medical staff. ${ }^{8}$

To date, the JD-R model is suitable for understanding employee well-being and occupational stress $^{9}$ from different occupational contexts. In the JD-R model, which is based on a value-based criterion, ${ }^{8}$ job characteristics across all occupations are divided into two categories: job demands and job resources. ${ }^{10}$ In general, job demands refer to the degree to which the duties and requirements of the job require physical, social or psychological (cognitive and emotional) efforts or skills from the employees. ${ }^{11}$ Job resources consist of a series of beneficial or support elements for the employees, mainly including physical, environmental, social or organisational aspects. ${ }^{11}$ If job demands are high and job resources are low, individual well-being may be threatened, resulting in higher psychosocial stress and low work motivation. The JD-R model has been tested and validated across a wide range of samples in different countries and industries. ${ }^{12}$ Previous studies provide a great deal of corroborating evidence from the investigation of job demands, resources and relevant outcomes among different groups of medical staff. ${ }^{13}$ The conflict among insufficient job resources and heavy job demands could bring a series of negative outcomes to doctors, ${ }^{14} 15$ such as higher occupational strain. Chinese doctors have developed dissatisfied attitudes and disturbed psychological health. ${ }^{16}$ Currently, more studies have revealed that both job demands and job resources among medical staff account for increasing job strain, burnout and worsened work outcomes. ${ }^{1013}$ Unfortunately, there are limited and inconclusive results on the impact of job demand-resource factors on various indicators with regard to work, life and well-being among Chinese doctors. As a positive motivator of an individual's overall job situation, job satisfaction is the degree to which an individual evaluates the quality of work life as a whole. ${ }^{17}$ Job and life satisfactions are regarded as two important attitudinal variables. ${ }^{18}$ Discussions in the field of organisational behaviour focus on job-related, health-related and motivational outcomes, such as turnover, commitment, public service motivation, work engagement and organisational citizenship behaviours. ${ }^{17-19}$ Inconsistently, some studies assert a negative relationship between job demands and satisfaction, but others report contradictory results, including a non-significant relationship, a positive relationship or a gender-specific relationship more complex than what is often assumed..$^{20}$ As such, the relationships among job demands, job satisfaction and life satisfaction need to be further explored. Moreover, prior studies indicated that high job demands are significantly associated with greater work-family conflicts. ${ }^{21}{ }^{22}$ As a role conflict, work-family conflicts often appear when an employee encounters a dilemma between work demands and family duties. ${ }^{23}$ Allen and colleagues ${ }^{24}$ confirmed a negative relationship between work-family conflicts and job and life satisfaction. Thus, we can assume that a high degree of job demands is likely to undermine doctors' job or life satisfaction through growing work-family conflicts. Analogously, one study conducted among Chinese middle-level managers suggested that work-family conflicts mediated the relationship between job-related demands and both job and overall life satisfaction. ${ }^{25}$ In fact, in the Chinese hospital industry, doctors devote less time and energy to their families due to both heavy workload and emotional exhaustion caused by intense interactions with patients; this aggravates both job and life dissatisfaction. ${ }^{166}$ Currently, little is known regarding the relationships and functional mechanisms among jobrelated demands, work-family conflicts, and job and life satisfaction in Chinese doctors. Therefore, the current study attempts to clarify these relationships.

In addition, a sense of thriving is crucial to improving doctors' well-being and is also related to a wide array of positive outcomes, such as mitigating burnout and boosting physical and mental health. ${ }^{27}$ Thriving at work is a positive psychological state characterised by learning and vitality in the workplace. ${ }^{28}$ More specifically, Spreitzer et al inferred that employees who are thriving experience personal growth marked both by a kind of feeling energised and alive and a sense of continually acquiring and applying knowledge. ${ }^{28} 29$ A meta-analysis study showed that thriving at work was associated with both individual characteristics (eg, psychological capital, work engagement) and relational characteristics (eg, perceived organisational support). ${ }^{28}$ These are potentially derived from the integration between job-related awareness and employees' evaluation of job resources. The conservation of resources $(\mathrm{COR})^{30}$ theory implies that resource-rich environments contribute to creating greater opportunities for vitality and learning for doctors, leading to more beneficial effects. The COR theory proposes that resource depletion can be psychologically damaging and weaken an employee's degree of psychological attachment, further blocking the sense of thriving at work. ${ }^{30}$ For doctors, the motivational process can be driven by adequate availability of job resources; this fosters learning and growth. Hence, this study aimed to test the relationship between job resources and thriving at work among Chinese doctors. In detail, perceived adequate job resources (eg, opportunities for career growth, personal development opportunities, clarity regarding job roles, pleasant work environment and perceived organisation support) are a significant symbol of how doctors believe their hospital treats them. ${ }^{31}{ }^{32}$ Moreover, prior study has demonstrated that increased job resources,${ }^{33}$ such as workplace support, can benefit the individual thriving at work by boosting the individual's attachment to the organisation. ${ }^{34}$ Job attachment refers to an employee's emotional attachment to, identification with and involvement in 
the organisation. ${ }^{35}$ Psychologically attached physicians tend to identify with their hospital's goals and values, which leads to a somewhat more stable response, such as expending additional energy to their organisation's arrangements ${ }^{35} 36$ or requirement of medical services. ${ }^{33}$ Moreover, Wiesenfeldt et $a l^{37}$ argue that adequate organisational resources enable doctors to believe that they have obtained enough respect and rewards from the hospital; this is likely to arouse their motivation for new knowledge and enthusiasm to reciprocate organisational support. Furthermore, previous studies also imply that job attachment mediates the association of an employee's perceived job resources and positive feelings, such as a sense of burnout and flourishing. ${ }^{38}{ }^{39}$ Therefore, the current study implies that doctors with high perceived job resources could enhance their sense of thriving at work by deepening psychological attachment with both components of vitality and learning.

\section{OBJECTIVES}

The preceding discussion highlights the three significant goals of our study: (1) to evaluate the status of perceived job demands and job resources among Chinese doctors; (2) to examine the mediating role of work-family conflicts in the relationship between perceived job demands and job and life satisfaction; and (3) to identify the mediating role of psychological attachment in the relationship between perceived job resources and thriving at work.

\section{METHODS}

\section{Subjects and procedures}

This study used an anonymous online questionnaire to conduct an internet survey in May 2016. The study used snowball sampling. The purpose and significance of this study were provided on the front page of the selfadministered questionnaire. First, a sampling framework was constructed. Approximately 30 cooperative partners for various regions were recruited as the original deliverers of the survey. The doctors who were originally selected were the original deliverers of the survey and were appointed to deliver the questionnaires to other doctors. Selected doctors were invited to click on a webpage link to access a self-administered questionnaire (https://www. wenjuan.com/). Subsequently, the webpage link was sent by the deliverers to other doctors via mobile phones. Participants' progress in the survey was monitored by the authors, and anyone could obtain some rewards after answering the questionnaire. After completing review of valid questionnaires, participants who have completed the questionnaires were thanked and rewarded. We checked the accuracy and completeness of the data and excluded questionnaires that did not meet the criteria. Two authors checked the consistency of all data. For data management and quality control, we strictly adhered to the inclusion criteria in selecting our final sample. The inclusion criteria were as follows: (1) a registered doctor;
(2) currently enrolled in hospital; and (3) consent and voluntary participation in the study. Finally, a total of 2617 doctors from 30 different cities provided sufficiently complete responses to be used in the study.

\section{Patient and public involvement}

It was not appropriate or possible to involve patients or the public in the design, or conduct, or reporting or dissemination plans of our research.

Informed consent was obtained from all participants and provided on the front page of the self-administered questionnaire.

\section{Measures}

The questionnaire comprised seven sections: demographic variables, job demands and job resources, work-family conflicts, job satisfaction, life satisfaction, psychological attachment, and thriving at work.

\section{Demographic characteristics and job characteristics}

In the current study, four demographic variables were collected: gender, age, marital status and educational level. Marital status was divided into three categories: unmarried, married, and divorced or widowed. Options for educational level included 'college degree or below', 'bachelor's degree', 'master's degree' and 'doctor's degree or above'. Four variables were used to assess job characteristics: professional categories, job tenure, daily work hours and work shifts.

\section{Job demands}

A total of seven items measured job demands. ${ }^{4041}$ A sample item for job demands is: 'I have an excessive amount of work to do every day'. The items were scored on a 5-point Likert scale ranging from 1 ('totally disagree') to 5 ('totally agree'), where higher scores represent higher degree of job demands. In this study, the Cronbach's alpha coefficient for the job demands scale was 0.882 .

\section{Job resources}

A total of seven items measured job resources. ${ }^{40} 41 \mathrm{An}$ example of an item enquiring about job resources is: 'I feel that I have enough learning opportunities in my work right now'. The items were scored on a 5-point Likert scale ranging from 1 ('totally disagree') to 5 ('totally agree'), where higher scores represent higher degree of job resources. In this study, the Cronbach's alpha coefficient for job resources was 0.787 .

\section{Work-family conflicts}

Work-family conflicts were tested using three items ${ }^{42}$ developed by Fein and Skinner. We asked the following questions: 'How often does your work keep you from spending the amount of time you would like to with family or friends?', 'How often does your work interfere with your responsibilities or activities outside of work?' and 'How often does your work interfere with your ability to develop or maintain connections and friendships in your community?' All responses were marked on a 5-point 
scale ranging from 1 ('never') to 5 ('almost always'), with higher scores indicating worse work-life conflict. In this study, the Cronbach's alpha coefficient was 0.906 .

\section{Job satisfaction}

The Job Satisfaction Scale used in this survey was proposed by Smith et al. ${ }^{43}$ It consisted of six items representing six job satisfaction domains: satisfaction with the job itself, leadership, colleagues, income, promotion opportunities and the job as a whole. The items were scored on a 5-point scale ranging from 1 ('totally disagree') to 5 ('totally agree'), where higher scores represent higher degree of job satisfaction. An unweighted sum of the scale was calculated as a rough indicator of overall satisfaction. In this study, the Cronbach's alpha coefficient was 0.912 .

\section{Life satisfaction}

The overall life satisfaction was estimated by a widely used single-item measure ('In general, are you satisfied with your current life?'). A 5-point scale ranging from 1 ('totally disagree') to 5 ('totally agree') was used to evaluate the item. High scores reflect high level of life satisfaction. ${ }^{44}$

\section{Psychological attachment}

The psychological attachment inventory developed by Burris $e t a l^{35}$ was used with four revised items to evaluate Chinese doctors' level of psychological attachment. A 5-point Likert scale was adopted, where 1 represents 'totally disagree' and 5 represents 'totally agree'. Sample items include 'I'd be happy to spend the rest of my career at current hospital' and 'Working at current hospital has a great deal of personal meaning for me'. Higher scores represent higher degree of psychological attachment. In this study, the Cronbach's alpha coefficient was 0.920 .

\section{Thriving at work}

Ten items developed by Porath and colleagues ${ }^{45}$ used a 5-point Likert scale ranging from 1 ('strongly disagree') to 5 ('strongly agree') to assess thriving at work. The two dimensions assessed were learning and vitality. Higher scores suggest doctors had a greater passion for learning and tend to strive for psychological growth. A sample item for learning is 'I continue to learn more and more as time goes by' and for vitality 'I feel alive and vital'. Of these, items 4 and 7 were reverse-scored. In the current study, the Cronbach's alpha coefficients for learning, vitality and the whole scale were $0.787,0.850$ and 0.861 , respectively.

\section{Statistical analysis}

Preliminary analyses

All data were collected using a cross-sectional survey. Analyses were performed using the SPSS V.22.0 program. Descriptive statistics were used to report the average values of the continuous variables. An internal consistency reliability test was used to assess the reliability of the scale. Pearson's correlation coefficients reflected the correlation between variables. Statistical significance was considered based on a two-tailed $\mathrm{p}<0.05$.

\section{Mediation analysis}

A series of hierarchical linear regression analyses were also performed to examine the relationships among the variables assessed after eliminating the effects of the demographic variables (gender, marital status, hospital level, service years, professional title, night shifts, work hours and educational level). The chain intermediary mechanism was analysed using the SPSS macro PROCESS provided by Hayes, ${ }^{46}$ specifically model 4 . All related analyses were subjected to bootstrapping (5000 bootstrap samples) using 95\% CI. The macro PROCESS was used to calculate and test the direct and indirect effects. We provided values including $F, r^{2}$ and $r^{2}$ changes; the fit of the model was assessed with $r^{2}$. Unstandardised regression coefficients $(B), \mathrm{SE}$ and $\mathrm{p}$ values were reported for each step in the regression model. Statistical significance was defined as $\mathrm{p}<0.05$ (two-tailed).

\section{RESULTS}

\section{Demographic information of the sample}

Of the 2617 doctors surveyed, most $(66.6 \%)$ were from tertiary hospitals. The age of the participants ranged from 20 to 53 years. Women made up $52.3 \%$ of the sample. Most $(82.1 \%)$ participants were married. As for educational background, $51.7 \%$ obtained a bachelor's degree and $38.1 \%$ obtained a master's or doctorate degree. A total of $306(11.7 \%)$ participants were without professional titles, $564(21.6 \%)$ were resident doctors, $898(34.4 \%)$ were attending physicians, 569 (21.8\%) were associate chief physicians and $270(10.4 \%)$ were chief physicians. Approximately $79.8 \%$ of the participants reported working more than 8 hours a day and frequently $61.6 \%$ worked at night.

\section{Correlation among variables}

The mean, SD and Pearson's correlation coefficients of the continuous variables are presented in table 1. Most of the variables significantly correlated with each other. The absolute value of the correlation coefficient was statistically significant; this indicated that each variable could be used in the subsequent regression analyses.

\section{Multiple linear hierarchical regression models}

The controlled variables for eliminating the effects included gender, marital status, hospital level, service years, professional title, night shifts, work hours and educational level. 'Job demands' and 'job resources' were regarded as independent variables, 'work-family conflicts' and 'psychological attachment' as mediator variables, and 'life satisfaction', 'job satisfaction' and 'thriving at work' as dependent variables. Job demands were expected to negatively affect life and job satisfaction among Chinese doctors. The results showed that perceived job demands of participants were positively associated with work-family 
Table 1 Mean, SD and correlations of continuous variables $(\mathrm{N}=2617)$

\begin{tabular}{|c|c|c|c|c|c|c|c|c|c|}
\hline Variables & $M$ & SD & 1 & 2 & 3 & 4 & 5 & 6 & 7 \\
\hline 1. Job demands & 3.843 & 0.791 & 1 & & & & & & \\
\hline 2. Job resources & 2.474 & 0.740 & -0.004 & 1 & & & & & \\
\hline 4. Life satisfaction & 2.586 & 0.803 & $-0.120^{\star \star}$ & $0.446^{\star \star}$ & $-0.405^{\star \star}$ & 1 & & & \\
\hline 5. Job satisfaction & 2.476 & 1.034 & $-0.244^{\star *}$ & $0.681^{\star *}$ & $-0.319^{\star *}$ & $0.519^{\star \star}$ & 1 & & \\
\hline 7. Psychological attachment & 3.698 & 1.134 & -0.003 & $0.664^{\star *}$ & $-0.290^{\star *}$ & $0.413^{\star *}$ & $0.666^{\star *}$ & $0.607^{* *}$ & 1 \\
\hline
\end{tabular}

${ }^{\star *} \mathrm{P}<0.01$, correlation is significant at the 0.01 level (two-tailed).

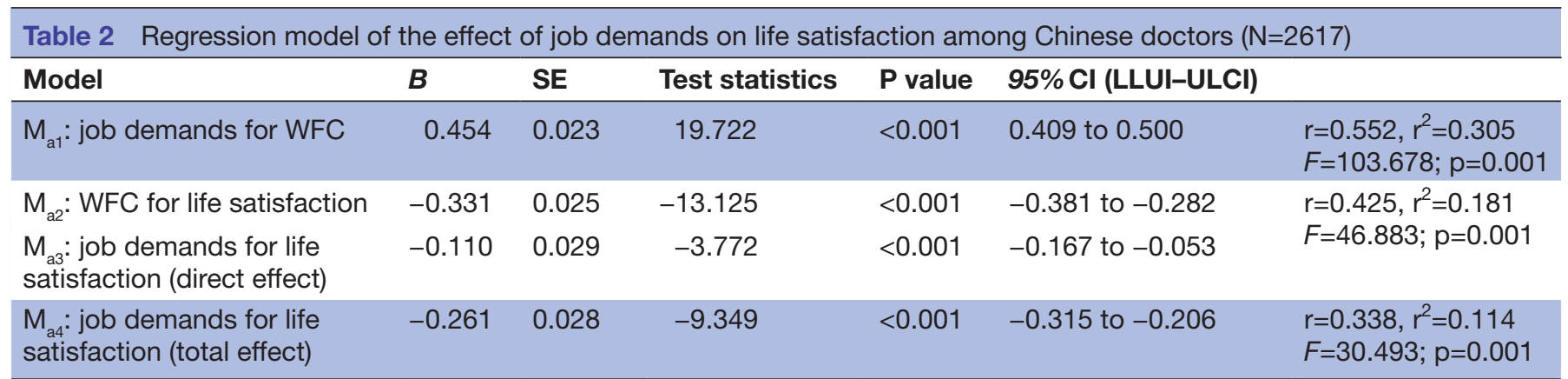

CI, Confidence interval; LLCI, Lower level confidence interval; ULCI, Upper level confidence interval; WFC, work-family conflicts.

conflicts $(B=0.454, \mathrm{p}<0.001)$ and negatively associated with job satisfaction $(B=-0.065, \mathrm{p}<0.001)$ and life satisfaction $(B=-0.261, \mathrm{p}<0.001)$. These assumptions are reflected by model ${ }_{\mathrm{a} 4}$ and model $_{\mathrm{b} 4}$ (tables 2 and 3 ). The findings also showed that work-family conflicts partially mediated the relationship between job demands and life satisfaction (see table 2 and figure 1) and fully mediated the relationship between job demands and job satisfaction (see table 3 and figure 1). Moreover, the current study confirmed that job resources had a positive effect on psychological attachment $(B=0.988, \mathrm{p}<0.001)$ and thriving at work $(B=0.988, \mathrm{p}<0.001)$, and psychological attachment partially mediated the relationship between them (see table 4 and figure 2).

\section{DISCUSSION}

In this study, we evaluated job demands and resources by administering a self-reported questionnaire to Chinese doctors. The current study focused on further understanding how perceived job demands and resources determine doctors' job and overall life satisfaction and how job and life satisfactions in turn contribute to an individual's sense of thriving in a Chinese hospital setting. Furthermore, our findings confirmed the mediating effect of work-family conflicts on the relationship between perceived job demands, job satisfaction and life satisfaction, respectively. We also found that

Table 3 Regression model of the effect of job demands on job satisfaction among Chinese doctors (N=2617)

\begin{tabular}{|c|c|c|c|c|c|c|}
\hline Model & $B$ & SE & Test statistics & $P$ value & 95\% CI (LLUI-ULCI) & \\
\hline$M_{a 5}:$ job demands for WFC & 0.455 & 0.023 & 10.726 & $<0.001$ & 0.410 to 0.500 & $\begin{array}{l}r=0.554, r^{2}=0.306 \\
F=103.907 ; p=0.001\end{array}$ \\
\hline$M_{a 6}:$ WFC for job satisfaction & -0.224 & 0.020 & -10.988 & $<0.001$ & -0.264 to -0.184 & \multirow{2}{*}{$\begin{array}{l}r=0.335, r^{2}=0.113 \\
F=26.826 ; p=0.001\end{array}$} \\
\hline $\begin{array}{l}M_{a 7}: \text { job demands for job } \\
\text { satisfaction (direct effect) }\end{array}$ & -0.037 & 0.024 & 1.562 & 0.119 & -0.009 to 0.083 & \\
\hline $\begin{array}{l}M_{a 8} \text { : job demands for job } \\
\text { satisfaction (total effect) }\end{array}$ & -0.065 & 0.022 & -2.932 & $<0.001$ & -0.109 to -0.002 & $\begin{array}{l}r=0.249, r^{2}=0.062 \\
F=15.514 ; p=0.001\end{array}$ \\
\hline
\end{tabular}

CI, Confidence interval; LLCI, Lower level confidence interval; ULCI, Upper level confidence interval; WFC, work-family conflicts. 
Table 4 Regression model of the effect of job resources on thriving at work among Chinese doctors $(\mathrm{N}=2617)$

\begin{tabular}{|c|c|c|c|c|c|c|}
\hline Model & $B$ & SE & Test statistics & $P$ value & 95\% CI (LLUI-ULCI) & \\
\hline $\begin{array}{l}M_{b 1}: \text { job resources for } \\
\text { psychological attachment }\end{array}$ & 0.988 & 0.026 & 38.692 & $<0.001$ & 0.937 to 1.038 & $\begin{array}{l}r=0.675, r^{2}=0.455 \\
F=194.937 ; p=0.001\end{array}$ \\
\hline $\begin{array}{l}M_{b 3}: \text { job resources for thriving at } \\
\text { work (direct effect) }\end{array}$ & 0.265 & 0.015 & 17.747 & $<0.001$ & 0.236 to 0.294 & \\
\hline
\end{tabular}

Cl, Confidence interval; LLCI, Lower level confidence interval; ULCI, Upper level confidence interval.

the relationship between perceived job resources and thriving at work was mediated by doctors' psychological attachment.

\section{Job demands and resources and thriving at work among Chinese doctors}

The participants in our survey had higher job demands $(M=3.843 \pm 0.791)$ than job resources $(M=2.474 \pm 0.740)$, which is consistent with a previous study. ${ }^{47}$ As for thriving at work, the mean value of participants' learning aspect $(M=3.037 \pm 0.756)$ was higher than the vitality aspect $(M=2.812 \pm 0.709)$. Most Chinese doctors reported that they had fast-paced work, which required more effort and higher quality professional skills. Given that lack of skilled and experienced health professionals has long been a problem in the Chinese healthcare system, ${ }^{48}$ Chinese doctors suffer from greater work stress and heavier workload in responding to patients' needs for high-quality healthcare. ${ }^{47}$ More importantly, doctors often devote considerable efforts to improve poor doctor-patient relationships. ${ }^{350}$ Chinese doctors expend greater resourcesextra time, energy and emotional labour-to satisfy the growing healthcare service demands of the general population, including having to bear with patients' distrust and animosity. ${ }^{51} \mathrm{~A}$ dilemma of the unbalance between job demands and resources is common among Chinese

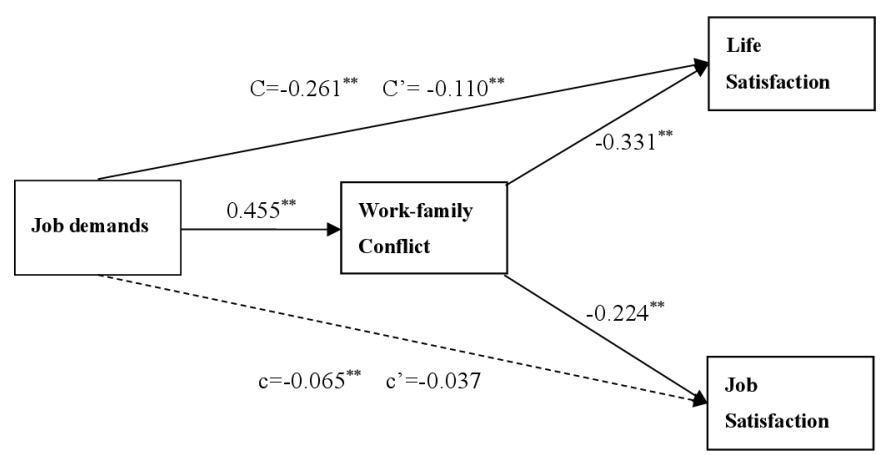

Figure 1 Model of pathways between job demands, job satisfaction and life satisfaction among Chinese doctors. Coefficients are unstandardised regression coefficients $(B)$. ${ }^{\star \star} \mathrm{P}<0.01$, coefficient is significant at the 0.01 level (twotailed). doctors, ${ }^{40} 41$ which must receive further adequate attention from hospital managers.

Association among job demands, work-family conflicts and doctor satisfaction in Chinese medical settings

Our evidence showed that doctors' job demands had a positive direct impact on increasing work-family conflicts $(B=0.454, \quad \mathrm{p}<0.001)$ and mitigating job satisfaction $(B=-0.065, \mathrm{p}<0.001)$, and exhibited a positive indirect impact on mitigating life satisfaction $(B=-0.261, \mathrm{p}<0.001)$ by aggravating work-family conflicts. Our results suggested that high degrees of job demands in the hospital setting do not directly affect doctors' job satisfaction; instead, job demands first trigger work-family conflicts, which then impact job satisfaction. The current study provided further evidence that doctors dealing with work-family conflicts are prone to experience greater job dissatisfaction when they encounter job demands from the hospital. The heavy demands placed on doctors may evoke strain or health impairment. Facing increasing job demands, doctors compensate by exerting more physical or psychological effort to maintain high-level performance. ${ }^{52}$ Continuous mobilisation of compensatory efforts drains doctors' energy, leading to increasing burnout and ill health, and eventually lowering job and life satisfaction. ${ }^{52}$ Moreover, as a collectivistic country, China places more emphasis on the virtues of philanthropy and altruism and less emphasis on self-interest than Western countries; as such, doctors in China tend to direct much energy and time to meeting job-related demands despite considerable opposition from their families ${ }^{53}$ Furthermore, role conflict occurs when doctors are unable to balance two

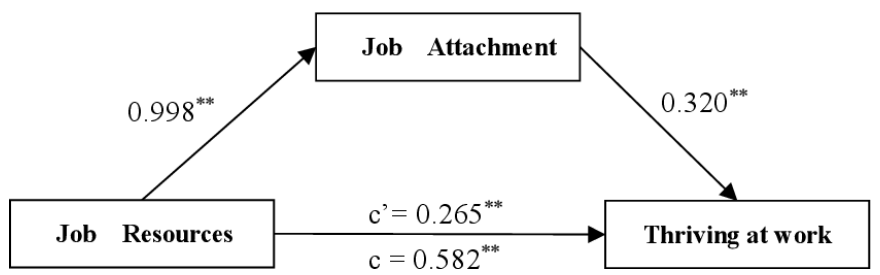

Figure 2 Model of pathways between job resources and thriving at work among Chinese doctors. Coefficients are unstandardised regression coefficients (B). ${ }^{\star *} \mathrm{P}<0.01$, coefficient is significant at the 0.01 level (two-tailed). 
or more roles at once. Due to limited energy and time, it is difficult for them to simultaneously fulfil their roles at work and in the family ${ }^{54}$; this results in diminished self-evaluation in both the job and in life..$^{55}$ Additionally, doctors may experience negative emotions from both jobrelated experiences and poorer interactions with family and friends; the negative feelings from these two factors can influence each other ${ }^{56}$ Indeed, due to the objective shortage of doctors in China, there is a considerable challenge to reduce job demands in a short amount of time $^{57}$; however, adequate support from others may blunt the negative effects of work-family conflicts, such as emotional exhaustion and cynicism, ${ }^{58}$ thus securing the quality of both the health of the patient and the life of the doctor. ${ }^{53}$ Overall, it is beneficial for hospital managers to help doctors work towards a more balanced approach to well-being by reducing excess workload, providing satisfactory support and mitigating the festering work-family conflicts.

\section{Association among job resources, job attachment and thriving at work in Chinese doctors}

Current findings that doctors with greater job resources are more likely to exhibit high-degree psychological attachment $(B=0.988, \mathrm{p}<0.001)$ and increased thriving at work $(B=0.582, \mathrm{p}<0.001)$ are consistent with previous studies. ${ }^{39}$ Furthermore, our findings confirmed that greater job resources boost doctors' levels of psychological attachment, leading to higher degrees of thriving at work. Similar conclusions were also proposed by Spreitzer et $a l .{ }^{29}$ In addition, the present study illustrated that the likelihood of doctors reporting a greater sense of thriving at work is likely to be driven by high levels of available job resources that can help them increase their psychological attachment to achieve career goals. Indeed, job resources are often instrumental in allowing doctors to perform their duties with engagement; this leads to high degrees of organisational commitment, inherent growth, learning and intrinsic work motivation. ${ }^{59}$ Traditionally, doctors form self-beliefs about the types of resources that they are obligated to provide to the hospital and that the hospital is obligated to provide to them in return. ${ }^{59}$ Specifically, no matter what the doctors require-such as skills utilisation, support, autonomy, feedback, learning opportunities, career opportunities and other resources-hospital organisations meet their needs; this further evokes doctors' intrinsic motivation and in turn inspires greater passion and positive emotion towards hospital work. ${ }^{60}$ According to the psychological contract theory, individuallevel cognitive structures determine how doctors think about their exchange relationship; this is regarded as the doctor's belief system regarding the obligation that exists between the doctors and the medical institutions that they work for. ${ }^{61}$ As such, by the reciprocity norm, doctors who obtained highly valued resources (eg, pay raises and developmental training opportunities) from the hospital are likely to emerge with a greater sense of responsibility and vitality towards their work or duty; consequently, they may dedicate more effort and ability to achieve their work-related goals and individual growth. ${ }^{62}$ Generally, job attachment is regarded as a stable response from doctors to the overall work situation and their perceived sense of security. ${ }^{5}$ Doctors with plenty of additional work-related resources will exhibit greater comfort and psychological security in the workplace ${ }^{63}$ in turn fostering their sense of stability, securing positive emotions and driving individual prosperity to pursue work-related goals. Overall, for hospital managers to help doctors thrive at work despite low-resource settings, doctors' psychological attachment to hospital organisations must be strengthened.

\section{Limitations}

This study offered a number of valuable discoveries. Nevertheless, some limitations should be considered. First, a convenience sample was adopted, which tends to increase potential sampling bias. Second is the crosssectional nature of the variables; ultimately, these results could not be regarded as describing a causal relationship. Third, considering a self-report method, it is possible that socioeconomic status affected how doctors reported on their life and work situation. Finally, we partly used foreign scales, which did not take into account issues of crosscultural adaptability, offering scope for academic attention in the future. The phenomenon of an unbalanced relationship between job demands and job resources is common in hospital settings, and its influence is extensive and pervasive. Therefore, longitudinal studies should be conducted in the future.

\section{CONCLUSION}

In sum, Chinese doctors suffered from high-level job demands and scarce job resources, resulting in declining job and overall life satisfaction and a lower sense of thriving at work; work-family conflicts mediated this relationship. Doctors who endured high job demands tended to exhibit increasing work-family conflicts, which in turn threatened their sense of job and overall life satisfaction. Doctors with greater job resources were more prone to thrive at work due to high levels of psychological attachment. The findings suggested that more psychological and social support should be provided by hospital managers and supervisors to Chinese doctors, as well as more working resources to balance their work demands, thus improving their life and job satisfaction and thriving at work.

Acknowledgements The authors thank all the doctors for their generous contributions to this research. The authors would also like to thank Editage (www. editage.cn) for English language editing.

Contributors TS and SEZ co-designed the research. TS, YS and SEZ performed the research. SEZ and YS analyzed the data. SEZ and BL wrote revised the manuscript. XZ, HNW and XHW substantively revised it. All authors read and approved the final manuscript.

Funding The authors have not declared a specific grant for this research from any funding agency in the public, commercial or not-for-profit sectors.

Competing interests None declared. 
Patient and public involvement Patients and/or the public were not involved in the design, or conduct, or reporting, or dissemination plans of this research.

\section{Patient consent for publication Not required.}

Ethics approval All procedures in this survey involving human participants were in accordance with the ethical standards of the institutional committee (Institutiona Review Board of Harbin Medical University). In addition, the research conformed to the principles embodied in the Declaration of Helsinki.

Provenance and peer review Not commissioned; externally peer reviewed.

Data availability statement Data are available upon reasonable request. The datasets used and/or analyzed during this study are available from the corresponding author on reasonable request from hydsuntao@126.com.

Open access This is an open access article distributed in accordance with the Creative Commons Attribution Non Commercial (CC BY-NC 4.0) license, which permits others to distribute, remix, adapt, build upon this work non-commercially, and license their derivative works on different terms, provided the original work is properly cited, appropriate credit is given, any changes made indicated, and the use is non-commercial. See: http://creativecommons.org/licenses/by-nc/4.0/.

\section{ORCID iDs}

Hongni Wang http://orcid.org/0000-0002-2491-3838

Tao Sun http://orcid.org/0000-0002-7690-2946

\section{REFERENCES}

1 Chen Q, Yang L, Feng Q, et al. Job satisfaction analysis in rural China: a qualitative study of doctors in a township Hospital. Scientifica 2017;2017:1-6.

2 Zhou M, Zhao L, Campy KS, et al. Changing of China's health policy and Doctor-Patient relationship: 1949-2016. Health Policy and Technology 2017:6:358-67.

3 Chinese doctors are under threat. Lancet 2010;376:657-57.

4 Xing $\mathrm{K}$, Zhang $\mathrm{X}$, Jiao $\mathrm{M}$, et al. Concern about workplace violence and its risk factors in Chinese township hospitals: a cross-sectional study. Int J Environ Res Public Health 2016;13:811-21.

5 Zhang Shu'e, Wang J, Xie F, et al. A cross-sectional study of job burnout, psychological attachment, and the career calling of Chinese doctors. BMC Health Serv Res 2020;20:193.

6 Sun T, Gao L, Li F, et al. Workplace violence, psychological stress, sleep quality and subjective health in Chinese doctors: a large crosssectional study. BMJ Open 2017;7:e017182.

7 Wu D, Hesketh T, Zhou X-D. Media contribution to violence against health workers in China: a content analysis study of 124 online media reports. The Lancet 2015;386:S81.

$8 \mathrm{Hu}$ Q, Schaufeli WB, Taris TW. Does equity mediate the effects of job demands and job resources on work outcomes?: an extension of the job demands-resources model. Career Development International 2013;18:357-76

9 Bakker AB, Demerouti E. The job Demands-Resources model: state of the art. Journal of Managerial Psych 2007;22:309-28.

10 Janse van Rensburg C, Rothmann S, Diedericks E. Job demands and resources: Flourishing and job performance in South African universities of technology settings. Journal of Psychology in Africa 2018;28:291-7.

11 Demerouti E, Bakker AB, Nachreiner F, et al. The job demandsresources model of burnout. J Appl Psychol 2001;86:499-512.

12 Schaufeli W, Taris T. A critical review of the job Demands-Resources model: implications for improving work and health. In: Bridging occupational, organizational and public health, 2013: 43-68.

13 Zis P, Anagnostopoulos F, Sykioti P. Burnout in medical residents: a study based on the job demands-resources model. ScientificWorldJournal 2014;2014:1-10.

$14 \mathrm{Ge} \mathrm{J,} \mathrm{He} \mathrm{J,} \mathrm{Liu} \mathrm{Y,} \mathrm{et} \mathrm{al.} \mathrm{Effects} \mathrm{of} \mathrm{effort-reward} \mathrm{imbalance,} \mathrm{job}$ satisfaction, and work engagement on self-rated health among healthcare workers. BMC Public Health 2021;21:195.

15 Babakus E, Yavas U, Karatepe OM. The effects of job demands, job resources and intrinsic motivation on emotional exhaustion and turnover intentions: a study in the Turkish hotel industry. International Journal of Hospitality \& Tourism Administration 2008;9:384-404.

16 Abid G, Zahra I, Ahmed A. Promoting thriving at work and waning turnover intention: a relational perspective. Future Business Journal 2016;2:127-37

17 Haar JM, Russo M, Suñe A, et al. Outcomes of work-life balance on job satisfaction, life satisfaction and mental health: a study across seven cultures. J Vocat Behav 2014;85:361-73.
18 Uchmanowicz I, Manulik S, Lomper K, et al. Life satisfaction, job satisfaction, life orientation and occupational burnout among nurses and midwives in medical institutions in Poland: a cross-sectional study. BMJ Open 2019;9:e024296.

19 Homberg F, McCarthy D, Tabvuma V. A Meta-Analysis of the relationship between public service motivation and job satisfaction. Public Adm Rev 2015;75:711-22.

20 Yeh $\mathrm{H}$-J. Job demands, job resources, and job satisfaction in East Asia. Soc Indic Res 2015;121:47-60.

21 Montgomery AJ, Panagopolou E, Benos A. Work-family interference as a mediator between job demands and job burnout among doctors. Stress and Health 2006;22:203-12.

$22 \mathrm{Gu}$ Y, Wang R. Job demands and work-family conflict in preschool teachers: the buffering effects of job resources and off-job recovery experiences. Current Psychology 2021;40:3974-85.

23 Maertz CP, Boyar SL, Maloney PW. A theory of work-family conflict episode processing. J Vocat Behav 2019;115:103331.

24 Allen TD, Herst DE, Bruck CS, et al. Consequences associated with work-to-family conflict: a review and agenda for future research. $J$ Occup Health Psychol 2000;5:278-308.

25 Gao L, Jin W. Work-Family conflict mediates the association between job demands and life and job satisfaction in Chinese Middle-Level managers. Curr Psychol 2015;34:311-20.

26 Liu J, Yu W, Ding T, et al. Cross-Sectional survey on job satisfaction and its associated factors among doctors in tertiary public hospitals in Shanghai, China. BMJ Open 2019;9:e023823.

27 Spreitzer G, Porath CL, Gibson CB. Toward human sustainability : How to enable more thriving at work. Organizational Dynamics 2012;41:155-62.

28 Kleine Anne-Kathrin, Rudolph CW, Zacher $\mathrm{H}$. Thriving at work: a meta-analysis. J Organ Behav 2019;40:973-99.

29 Spreitzer G, Sutcliffe K, Dutton J, et al. A socially embedded model of thriving at work. Organization Science 2005;16:537-49.

30 Hobfoll SE. The influence of culture, community, and the Nested-Self in the stress process: advancing conservation of resources theory. Appl Psychol 2001;50:337-421.

31 Abid G, Zahra I, Ahmed A. Mediated mechanism of thriving at work between perceived organization support, innovative work behavior and turnover intention. Social Science Electronic Publishing 2016;4:297-9.

32 Zagenczyk TJ, Scott KD, Gibney R, et al. Social influence and perceived organizational support: a social networks analysis. Organ Behav Hum Decis Process 2010;111:127-38.

33 Kotzé M, Nel P. The influence of job resources on platinum mineworkers' work engagement and organisational commitment: An explorative study. The Extractive Industries and Society 2020;7:146-52.

34 Zhai $\mathrm{Q}$, Wang S, Weadon $\mathrm{H}$. Thriving at work as a mediator of the relationship between workplace support and life satisfaction. Journal of Management \& Organization 2020;26:168-84.

35 Burris ER, Detert JR, Chiaburu DS, Dan S C. Quitting before leaving: the mediating effects of psychological attachment and detachment on voice. J Appl Psychol 2008;93:912.

36 Koch JL, Steers RM. Job attachment, satisfaction, and turnover among public sector employees. J Vocat Behav 1978;12:119-28.

37 Wiesenfeldt M, Parlitz U, Lauterborn W. Mixed state analysis of multivariate time series. Int. J. Bifurcation Chaos 2001;11:2217-26.

38 Schaufeli WB, Bakker AB. Job demands, job resources, and their relationship with burnout and engagement: a multi-sample study. $J$ Organ Behav 2004;25:293-315.

39 Niessen C, Sonnentag S, Sach F. Thriving at work-A diary study. J Organ Behav 2012;33:468-87

40 Buys C, Rothmann S. Job demands and job resources in the Ministry. SA Journal of Human Resource Management 2009;7.

41 Wang S, Xie FZ, Yu S. Development of the job Demand-Resource scale for physicians and its impact on Work-Family conflict. Chinese Hospital Management, 2017.

42 Fein EC, Skinner N. Clarifying the effect of work hours on health through work-life conflict. Asia Pacific Journal of Human Resources 2015;53:448-70.

43 Smith PC, Kendall LM, Hulin CL. The measurement of satisfaction in work and retirement: a strategy for the study of attitudes. Attitude Measures 1969;45:194.

44 Jovanović V, Lazić M. Is longer always better? A comparison of the validity of single-item versus Multiple-item measures of life satisfaction. Appl Res Qual Life 2020;15:675-92.

45 Porath C, Spreitzer G, Gibson C, et al. Thriving at work: toward its measurement, construct validation, and theoretical refinement. $J$ Organ Behav 2012;33:250-75. 
46 Hayes A. Introduction to mediation, moderation, and conditional process analysis. Journal of Educational Measurement 2013;51:335-7.

47 The Lancet. The doctors' predicament: China's health-care growing pains. The Lancet 2019;393:1569.

48 Guan X, Ni B, Zhang J, et al. Association between physicians' workload and prescribing quality in one tertiary hospital in China. $J$ Patient Saf 2020. doi:10.1097/PTS.0000000000000753. [Epub ahead of print: 07 Aug 2020].

49 Wu D, Lam TP, Lam KF, et al. Doctors' views of patient expectations of medical care in Zhejiang Province, China. Int J Qual Health Care 2017;29:867-73.

50 Ma S, Xu X, Trigo V. Doctor-Patient relationships (Dpr) in China: managers and clinicians' twofold pathways from commitment HR practices. Journal of Health Organisation and Management 2017;31:110-24.

51 Sun T, Gao L, Li F, et al. Workplace violence, psychological stress, sleep quality and subjective health in Chinese doctors: a large crosssectional study. BMJ Open 2017;7:e017182.

52 Ryan RM, Deci EL. Self-determination theory and the facilitation of intrinsic motivation, social development, and well-being. Am Psychol 2000;55:68-78

53 Hao J, Wang J, Liu L, et al. Perceived organizational support impacts on the associations of Work-Family conflict or Family-Work conflict with depressive symptoms among Chinese doctors. Int J Environ Res Public Health 2016;13:326.

54 Spector PE, Allen TD, Poelmans SAY, et al. Cross-National differences in relationships of work demands, job satisfaction, and turnover intentions with WORK-FAMILY conflict. Pers Psychol 2007;60:805-35.

55 Boles J, Wood J, Johnson-Busbin J. Interrelationships of role conflict, role ambiguity, and Work-Family conflict with different facets of job satisfaction and the moderating effects of gender. Journal of Personal Selling \& Sales Management 2013;23:99-113.

56 Lambert E, Liu J, Jiang S. Examining the association between work-family conflict and the work attitudes of job satisfaction and organizational commitment among Chinese correctional staff. Psychiatry, Psychology and Law 2020:1-20.

$57 \mathrm{Li} \mathrm{H}$, Liu K, Gu J, et al. The development and impact of primary health care in China from 1949 to 2015: a focused review. Int $J$ Health Plann Manage 2017;32:339-50.

58 Zhang H, Tang L, Ye Z, et al. The role of social support and emotional exhaustion in the association between work-family conflict and anxiety symptoms among female medical staff: a moderated mediation model. BMC Psychiatry 2020;20:266.

59 Elfering A, Gerhardt C, Grebner S, et al. Exploring SupervisorRelated job resources as mediators between supervisor conflict and job attitudes in hospital employees. Saf Health Work 2017;8:19-28

60 Chmielewska M, Stokwiszewski J, Filip J, et al. Motivation factors affecting the job attitude of medical doctors and the organizational performance of public hospitals in Warsaw, Poland. BMC Health Serv Res 2020;20:701.

61 Aselage J, Eisenberger R. Perceived organizational support and psychological contracts: a theoretical integration. J Organ Behav 2003;24:491-509.

62 Markovits Y, Davis AJ, van Dick R. Organizational commitment profiles and job satisfaction among Greek private and public sector employees. International Journal of Cross Cultural Management 2007;7:77-99.

63 Scheepers RA, Lases LSS, Arah OA, et al. Job resources, physician work engagement, and patient care experience in an academic medical setting. Acad Med 2017;92:1472-9. 